\title{
Solar PV System Performance Ratio Evaluation for Electric Vehicles Charging Stations in Transit Oriented Development (TOD) Areas
}

\author{
Kianda Dhipatya Syahindra ${ }^{1,2}$, Samsul Ma'arif ${ }^{2}$, Aditya Anindito Widayat ${ }^{1,2}$, Ahmad Fakhrul Fauzi ${ }^{1,2}$, and Eko Adhi \\ Setiawan ${ }^{1,2, *}$ \\ ${ }^{1}$ Department of Electrical Engineering, Universitas Indonesia, Kampus UI Depok 16424, Indonesia \\ ${ }^{2}$ Tropical Renewable Energy Center, Faculty of Engineering, Universitas Indonesia, Kampus UI Depok 16424, Indonesia
}

\begin{abstract}
Transit Oriented Development (TOD) areas are locations that have limited land area. Solar PV systems are planned to be installed in these areas to support electric vehicles such as e-scooters, electric cars, motorcycles, and buses. However, solar PV systems in general require a large land area. The purpose of this paper is to find out and compare the Performance Ratios (PR) of a solar PV system installed on the rooftop with a floating solar PV system installed on the lake to determine which solar PV system fits better for TOD areas. PR analysis uses two methods, PVSyst software simulation and is validated using mathematical calculations. The result of the PR of floating solar PV is $76.39 \%$ using PVSyst simulation and $80.24 \%$ using mathematical calculation. Meanwhile, the PR of rooftop solar PV is $82.69 \%$ using PVSyst simulation and $73.41 \%$ using mathematical calculation. The significant factors that influence PR value are the energy produced by the solar PV system, its losses, and albedo value of the reflector surface for bifacial solar PV. Albedo value has to be maximized in order to obtain a higher performance ratio value. Based on this study, both rooftop and floating PV systems are equally suitable for TOD areas.
\end{abstract}

\section{Introduction}

Transit Oriented Development (TOD) areas are locations that have limited land area. As a city planning concept, TOD is designed and developed to improve land use efficiency. TOD areas are comprehensive with a variety of land uses. The comprehensiveness means that there are various social and public facilities that can fulfill a human's needs. With comprehensiveness and efficient land use, the TOD system should be capable to reduce dependency of fossil-fueled transportation and decrease emissions by using electric vehicles [1]. In order to power these vehicles, solar PV systems can be deployed.

Solar PV systems are viewed as a potential source for electric vehicles' charging stations in order to provide electricity for the vehicles from renewable energy sources and reduce emissions of greenhouse gases and harmful particles. Several studies have been conducted on this particular area. Tanveer, et al. investigated the possibility of using solar energy to charge electric vehicles in India [2]. Another research studied different scenarios for electric vehicle and solar PV integration in two Scandinavian cities, namely Tromso, Norway and Uppsala, Sweden [3]. Moreover, a different research was carried out to propose a strategy for solar-powered electric vehicle charging networks based on category prioritization [4].

Solar PV technology will change the main source of clean energy in the next few years as PV systems have been proven to be durable, reliable, and cost effective [5] It is one of the most effective, sustainable and inexpensive ways to produce renewable energy. However, the most important problem is the large land requirement, especially for densely populated and TOD areas $[1,6]$. Solar PV performance is affected by various environmental parameters related to location, temperature, spectral effect, tilt angle, shading effect, radiation level, and dust and dirt effect $[5,7]$.

The efficiency of solar PV modules and the performance of the PV systems have improved steadily over the last few decades. System performance is usually evaluated by analyzing the performance ratio (PR) [8]. $\mathrm{PR}$ is a measure of the performance of a PV system taking into account environmental factors (temperature, irradiation, climate change, etc.). PR can be used as a direct indicator for comparing differently designed systems, the same system design but established in a different location, or for evaluation of a PV system over time [8]. For example, PR was used in a research comparing performances of bifacial PV with three commercial monofacial PV technologies at the Atacama Desert in Chile [9].

PV Systems with different locations and installed capacities can be compared in terms of the performance ratio (PR). Several types of solar panel (PV) installations include: rooftop, ground mounted, canal top and floating [10]. There are many bodies of water available in Indonesia which can reduce land costs and operating

Corresponding author: ekoas@eng.ui.ac.id 
costs for electricity generation [10, 11]. Floating solar PV has an advantage over ground and rooftop mounting systems due to its cooling effect. It also reduces reservoir or lake evaporation and algae growth by shading the water. However, rooftop PV systems are easily installed in areas packed with buildings. The purpose of this paper is to find out and compare the performance ratios of a rooftop solar PV system with a floating solar PV system to determine which system fits better for TOD areas and integrated with electric vehicles' charging stations.

\section{Methodology}

The location of the floating solar PV system on Lake Mahoni, Universitas Indonesia has coordinates of $6^{\circ} 21^{\prime} 47.0^{\prime \prime} \mathrm{S} 106^{\circ} 49^{\prime} 33.4^{\prime \prime} \mathrm{E}$ with a capacity of $9.36 \mathrm{kWp}$ which requires an area of the lake to be covered by 165 $\mathrm{m}^{2}$ of floating solar PV. As for the location of the rooftop solar PV system, it has coordinates of $6^{\circ} 21^{\prime} 44.1^{\prime \prime S} 106^{\circ} 49^{\prime} 31.0^{\prime \prime} \mathrm{E}$, and is installed above the Engineering Center Building of the Faculty of Engineering, Universitas Indonesia with a capacity of $41.1 \mathrm{kWp}$ which requires a roof area of $460 \mathrm{~m}^{2}$. The rooftop PV system and floating PV system can be seen in Figure 1. Energy and power data from the system can be accessed through the Sunny Portal website, where the data is used to calculate PR using a mathematical equation and compared with simulation results from the PVSyst software. The difference in installed power capacity and land requirements between the two systems is very significant. However, the two systems will be compared in terms of system performance by evaluating and analyzing the performance ratios (PR).

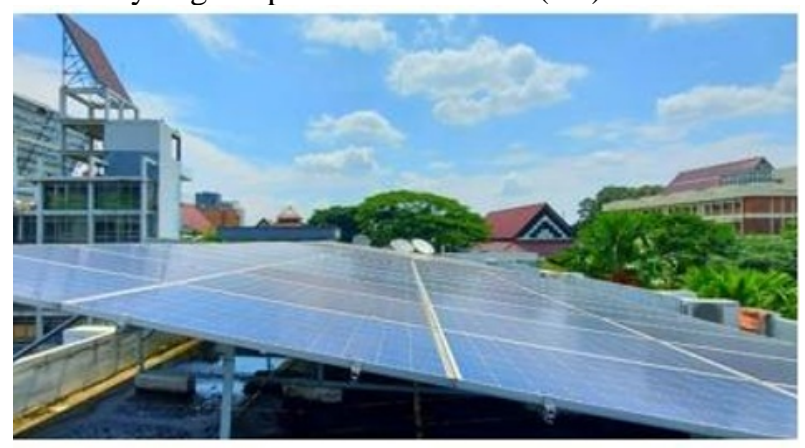

(a)

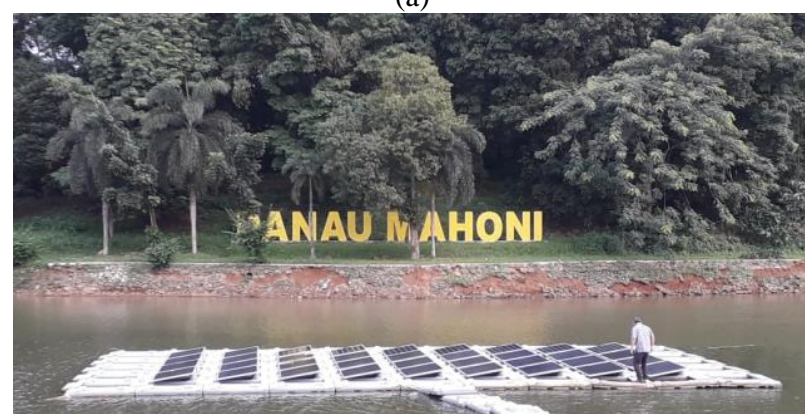

(b)

Fig. 1. (a) Rooftop Solar PV System and (b) Floating Solar PV System

The floating solar PV system installed is $9.36 \mathrm{kWp}$ with 36 panels of modules and 2 inverters with $5 \mathrm{~kW}$ power per inverter. Meanwhile, the rooftop solar PV has an installed capacity of $41.1 \mathrm{kWp}$ with 160 modules and 2 inverters with a power of $20 \mathrm{~kW}$ per inverter. The two systems are connected to the electrical grid at the Faculty of Engineering, Universitas Indonesia. The capacity of one panel in the Floating solar PV system is $260 \mathrm{Wp}$ and the capacity of one panel in the rooftop solar PV is 320 $\mathrm{Wp}$, more details can be seen in Table 1. The configuration of the floating and rooftop solar PV systems can be seen in Figure 2, where the systems are connected to the electric utility grid. In floating solar PV, the bifacial PV uses water as a light reflector on the back side of the PV, where the albedo value of water is 0.1 or $10 \%[8,9]$.

The formula for calculating PV performance ratio:

$$
P R=\frac{\text { Actual reading of plant output }}{\text { Calculated reading of plant output }}
$$

The calculated reading of plant output contains the result of the following calculation:

$$
G H I \times \text { Area } \times \% \text { Eff }
$$

Legend:

$$
\begin{aligned}
& G H I=\text { Global Horizontal Irradiation }\left(\frac{k w h}{m^{2}}\right) \\
& \text { Area }=\text { PV surface area }\left(m^{2}\right) \\
& \% E f f=\text { PV module efficiency }
\end{aligned}
$$



Fig. 2. Floating and Rooftop Solar PV Diagram

Table 1. PV Module Specifications

\begin{tabular}{|l|c|c|}
\hline \multicolumn{1}{|c|}{$\begin{array}{c}\text { Electrical } \\
\text { Specification }\end{array}$} & $\begin{array}{c}\text { Floating Solar } \\
\text { PV }\end{array}$ & $\begin{array}{c}\text { Rooftop } \\
\text { Solar PV }\end{array}$ \\
\hline Rated Power (Pmpp) & $260 \mathrm{Wp}$ & $320 \mathrm{Wp}$ \\
\hline $\begin{array}{l}\text { Rated Current } \\
\text { (Impp) }\end{array}$ & $8.50 \mathrm{~A}$ & $8.69 \mathrm{~A}$ \\
\hline $\begin{array}{l}\text { Rated Voltage } \\
\text { (Vmpp) }\end{array}$ & $30.59 \mathrm{~V}$ & $36.8 \mathrm{~V}$ \\
\hline $\begin{array}{l}\text { Short Circuit } \\
\text { Current (Isc) }\end{array}$ & $9.07 \mathrm{~A}$ & $9.26 \mathrm{~A}$ \\
\hline $\begin{array}{l}\text { Open Circuit } \\
\text { Voltage (Voc) }\end{array}$ & $38.24 \mathrm{~V}$ & $45.3 \mathrm{~V}$ \\
\hline
\end{tabular}

\section{Results and discussion}

\subsection{Performance ratio calculation}

To calculate the performance ratios, equation (1) is used. Due to the locations of the floating solar PV and rooftop solar PV system which are close to each other, the Global Horizontal Irradiation (GHI) is considered the same, which is $4.61 \mathrm{kWh} / \mathrm{m}^{2}$. The sampling time used was 162 days, starting from 20 February 2020 until 31 July 2020, because the floating PV system just started 
operating on February 19, 2020. Within this period, the temperature ranged between 22 and 35 degrees Celcius.

For the floating PV system with a PV surface area of $57.9 \mathrm{~m}^{2}, \mathrm{PV}$ efficiency of $16.7 \%$, and the actual energy sent to the grid for 162 days is $5832.52 \mathrm{kWh}$, the calculated performance ratio is:

$$
P R=\frac{5832.52}{4.64 \times 162 \times 57.9 \times 0.167}=80.24 \%
$$

For the rooftop PV System with a PV surface of 320 $\mathrm{m}^{2}$, PV efficiency of $16.2 \%$, and the actual energy sent to the grid for 162 days is $37747.27 \mathrm{kWh}$, then the performance ratio is:

$$
P R=\frac{37747.27}{4.64 \times 162 \times 320 \times 0.162}=73.41 \%
$$

Based on the mathematical equation of -.. performance ratio, which is a comparison between the actual energy and the calculated energy, the factors that affect the PR further are the energy produced by solar $\mathrm{PV}$ along with the losses. The two graphs in Figure 3 show the comparison of the PR between floating PV system and rooftop PV system using simulation with PVSyst and mathematical calculations from actual data.

There are differences in the values of the PR from the two methods used. For the floating PV system, this is because the mathematical PR calculation only accounts the front side of the panels, so that the sunlight received by the bifacial PV at the rear side due to water reflection is not included, whereas PVSyst simulation includes it. The additional output from the rear side of the bifacial $\mathrm{PV}$ increases the divisor in the PR equation leading to a lower PR result. For the rooftop PV system, this is due to heat reflected by the concrete below the PV modules which is not considered in the PVSyst simulation.

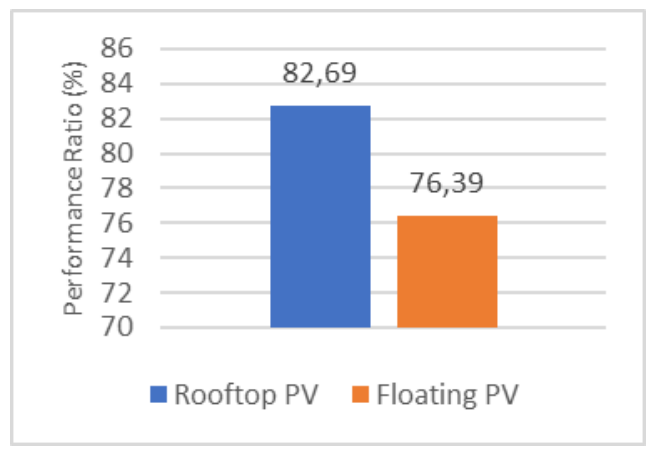

(a)

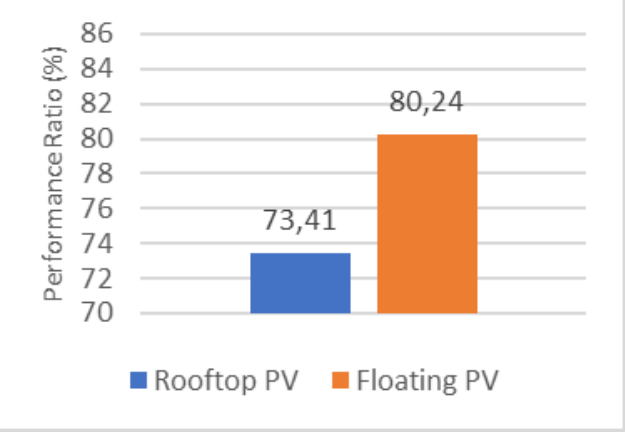

(b)

Fig. 3. Performance Ratio Results using (a) PVSyst Simulation and (b) Mathematical Calculations

\subsection{Floating PV system losses analysis}

Loss diagram for the floating PV system is shown at Figure 4. Annual global horizontal irradiation received by the floating PV system is $1731 \mathrm{kWh} / \mathrm{m}^{2}$. Because the system uses bifacial $\mathrm{PV}$, there is additional solar irradiation reaching the reflecting surface at the bottom of the PV by $526 \mathrm{kWh} / \mathrm{m}^{2}$. In this system, because it uses water, with an albedo value of 0.1 as a reflector, only $10 \%$ of the solar irradiance can be reflected back, and only $55.3 \%$ can be absorbed by PV after the reflection process from the water. Thus, this Bifacial PV produces an additional $2 \%$ of energy from the Global Horizontal Irradiation, or $34 \mathrm{kWh} / \mathrm{m}^{2}$. After deducting the power losses and the addition of the rear side of the bifacial, during the solar irradiance conversion process, the array nominal energy at Standard Testing Condition (STC) is 16.20 MWh. Furthermore, after losses due to irradiance level $(-4.3 \%)$, temperature $(-11.1 \%)$, and inverter ($6.5 \%)$, the resulting energy sent to the grid is 12.53 MWh per year.



Fig. 4. Loss Diagram of Floating PV

\subsection{Rooftop PV system losses analysis}

Loss diagram of the rooftop PV system is shown at Figure 5. Annual global horizontal irradiation received by rooftop solar PV system is $1732 \mathrm{kWh} / \mathrm{m}^{2}$. Due to the Incidence Angle Modifier (IAM) factor, irradiation is reduced by $2 \%$. So that the effective irradiance on collectors is $1719 \mathrm{kWh} / \mathrm{m}^{2}$. After the PV irradiance conversion of $16.45 \%$, the array nominal energy becomes 87.9 MWh. Furthermore, after losses due to irradiance level $(-0.7 \%)$, temperature $(-10.7 \%)$, and inverter $(-2.1 \%)$, the resulting energy sent to the grid is 74.3. MWh per year. 


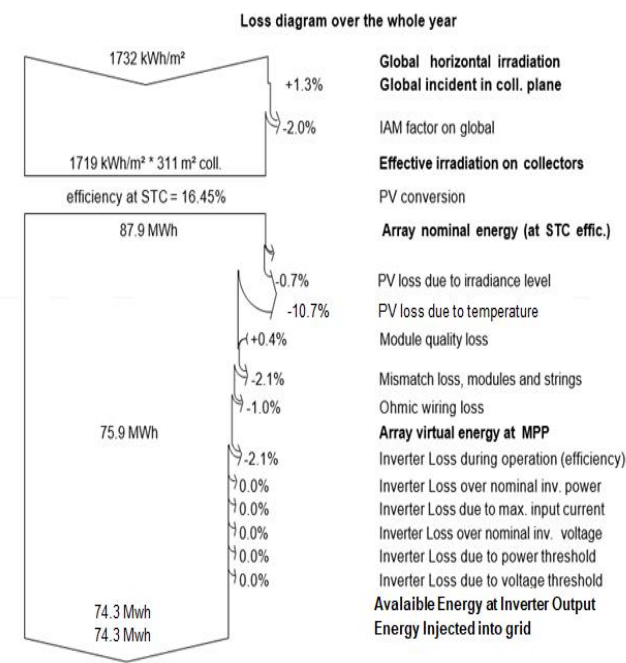

Fig. 5. Loss Diagram of Rooftop PV


Fig. 6. Electric Vehicles Floating PV Charging Station

From both systems' loss diagrams, there are significant losses due to temperature, $11.1 \%$ at the floating PV system and $10.7 \%$ at the rooftop PV system. These are caused by Indonesia's position which is in a tropical region, which has high temperatures.

In addition, due to using bifacial PV, the floating PV system experiences additional losses which results in a lower performance ratio compared to the rooftop PV system.

\subsection{Albedo variation on floating PV system}

Based on the loss diagram in Figure 4, only an additional $2 \%$ of Global Horizontal Irradiation enters the rear side of floating PV system. This is due to the large number of losses during the process of reflecting sunlight, where the ground reflection loss is influenced by the albedo value of the reflecting surface. In the actual condition, the reflector is water with an albedo value of 0.1 . Therefore, to increase performance ratio, a variety of reflecting surfaces that have different albedo values is simulated using PVSyst.

The simulation uses 6 types of reflecting surfaces with different albedo values [12, 13]. The six types of reflecting surfaces can be seen in Table 2 .

Table 2. Albedo values of Different Surface Types

\begin{tabular}{|l|c|}
\hline \multicolumn{1}{|c|}{ Name } & Albedo Value \\
\hline Bare Soil & 0.17 \\
\hline Desert Sand & 0.4 \\
\hline Fresh Asphalt & 0.04 \\
\hline Green Grass & 0.25 \\
\hline New Concrete & 0.55 \\
\hline Worn Asphalt & 0.12 \\
\hline
\end{tabular}

The albedo values in Table 2 are used in the PVSyst simulations to compare the values of the resulting system performance ratios. The simulation results can be seen in Figure 7. In the actual condition, the value of the performance ratio is $76.39 \%$ which is using lake water. Based on the simulation results, the highest performance ratio obtained is by using new concrete at $81.02 \%$, and the lowest performance ratio obtained is by using fresh asphalt at $75.77 \%$. Table 3 shows the global irradiance on rear side for each reflector surface.

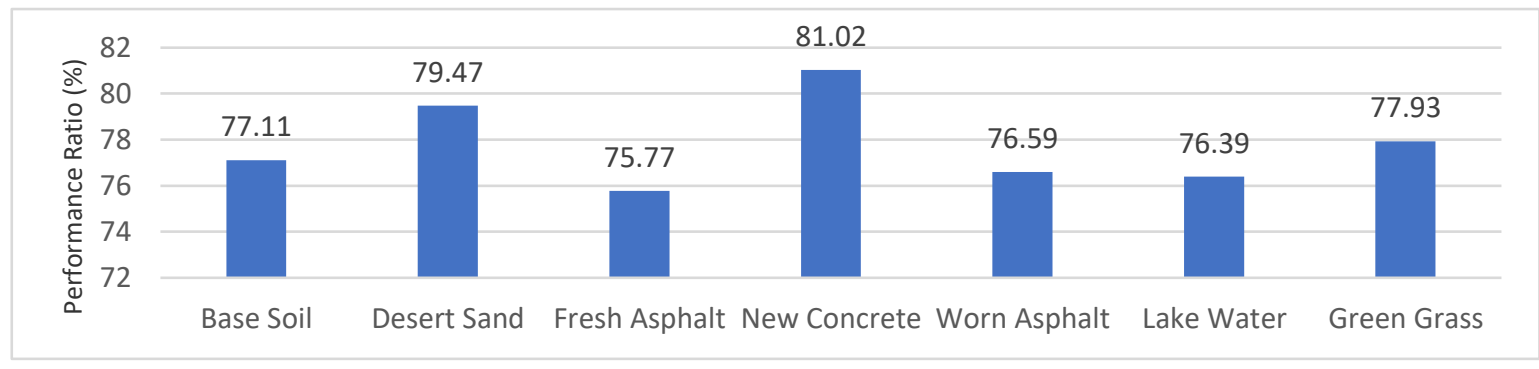

Fig. 7. Performance Ratio with Different Surface Types 
Table 3. Irradiance on rear side results from PVSyst simulation

\begin{tabular}{|l|c|c|}
\hline \multicolumn{1}{|c|}{ Name } & $\begin{array}{c}\text { Global } \\
\text { irradiance on } \\
\text { rear side }(\%)\end{array}$ & $\begin{array}{c}\text { Global } \\
\text { irradiance on } \\
\text { rear side }(\mathrm{kWh})\end{array}$ \\
\hline Bare Soil & 3.3 & 56 \\
\hline Desert Sand & 7.7 & 132 \\
\hline Fresh Asphalt & 0.8 & 14 \\
\hline Green Grass & 4.8 & 83 \\
\hline New Concrete & 10.6 & 181 \\
\hline Worn Asphalt & 2.4 & 40 \\
\hline Lake Water & 2.0 & 34 \\
\hline
\end{tabular}

Based on these results, it is known that in order to increase the performance ratio of a system using bifacial $\mathrm{PV}$, the albedo value of the reflecting surface is one of the parameters that must be considered by selecting the reflecting surface that has the highest albedo value.

\section{Conclusion}

Performance ratios of the floating PV system and the rooftop PV system are calculated using two methods, namely simulation using PVSyst and mathematical calculations. Based on the PVSyst simulation, the performance ratio of floating PV system is $76.39 \%$ and rooftop PV system is $82.69 \%$. The performance ratio from mathematical calculations of the floating PV system is $80.24 \%$ and the rooftop PV system is $73.41 \%$. There are differences in the performance ratio results between the PVSyst and the mathematical results, because the rear side of the bifacial floating PV panels not included in the mathematical calculation and heat reflected from the concrete below the rooftop solar PV system is not considered in the PVSyst simulation. The performance ratio of each PV system is affected by its energy production, where the components of losses in monofacial and bifacial PV are different. In order to increase the performance ratio of the bifacial PV system, the albedo value of the surface must be maximized. Both systems have similar PR values, the difference between both maximum PR values is only around $2.45 \%$. Based on these results, both systems should be equally suitable for installation in TOD areas and implementation choice should be based on the location's available resources.

The Authors would like to thank "Hibah Konsorsium Riset Unggulan Perguruan Tinggi No. NKB1077/UN2.R3.1/HKP.05.00/2019” for supporting and funding this work.

\section{References}

1. I. M. Putra, A. Prakoso, E. A. Setiawan, The Utiliz. of E-Scooter on Green Trans. Orien. Develop. Conc. in Tropic. Countries, AIP Conference Proceedings 2255, 020045 (2020)

2. M. S. Tanveer, S. Gupta, R. Rai, N. K. Jha, M. Bansal, Solar based electric vehicle charging station (IEEE, 2019)

3. C. Good, M. Shepero, J. Munkhammar, T. Bostrom, Scen.-based mod. of the potent. for solar energy charg. of elec. veh. in two Scandinavian cit., Energy 168, 111-125 (2019)

4. A. M. Alsomali, F. B. Alotaibi, A. T. Al-Awami, Charging strategy for electric vehicles using solar energy (IEEE, 2017)

5. I. R. Fiances, E. M. Cerón, R. E. Paredes, G. N. and J. de la Casa, Analysis of the Performance of Various PV Module Technologies in Peru (Energies, 2019)

6. J. G. Etxebarria. Toolbox for the design and simulation of a floating bifacial PV plant with reflectors (Thesis - TU Delft, 2018)

7. M. De Prada-Gil, J. L. Domínguez-García, L. Trilla, O. Gomis-Bellmunt, Technical and economic comparison of various electrical collection grid configurations for large photovoltaic power plants, IET Renew. Power Gener. 2017, 11, 226-236.

8. N. H. Reich, B. Mueller, A. Alfons, Wilfried G. J. H. M. van Sark, Klaus K., C. Reise, Performance ratio revisited: is PR > 90\% realistic?. (Prog. Photovolt: Res. Appl. 20, 717-726 (2012)

9. P. Ayala, C. Munoz, N. Osorio, C. Hernandez, F. Zurita, V. Gutierrez, G. Ramirez, F. Mancilla, P. Valdivia, F. Cuevas, P. Ferrada, Bifacial Technology Performance Compared With Three Commercial Monofacial PV Technologies under Outdoor High Irradiance Conditions at the Atacama Desert (IEEE, 2018)

10.A. Sahu, N. Yadav, K. Sudhakar, Floating photovoltaic power plant: A review. Renewable and Sustainable Energy Reviews 66, 815-824 (2016).

11.S. Yashpal, Shahabuddin M., P. Agrawal, Floating solar photovoltaic system: an emerging technology. (NSPCEP II, 2015)

12. R. G. Barry, R. J. Chorley, Atmosphere, Weather, and Climate, 4th ed. (Methuen, 1982).

13.W. D. Sellers, Physical Climatology (University of Chicago Press, 1965). 